\title{
AVALIAÇÃO DOS FITORREGULADORES AUXINA E GIBERELINA NA GERMINAÇÃO E CRESCIMENTO DO ARROZ
}

\author{
Luana Pedroso \\ Juliana Leme Bertoldo ${ }^{1}$ \\ Bianca de Almeida Marchi ${ }^{1}$ \\ Rayane Monique Sete da $\mathrm{Cruz}^{2}$ \\ Bruna Caroline de Souza ${ }^{2}$ \\ Caroline Lermen ${ }^{3}$ \\ Odair Alberton ${ }^{4}$
}

PEDROSO, L.; BERTOLDO, J. L.; MARCHI, B. de A.; CRUZ, R. M. S. da; SOUZA, B. C. de; LERMEN, C.; ALBERTON, O. Avaliação dos fitorreguladores auxina e giberelina na germinação e crescimento do arroz. Arq. Ciênc. Vet. Zool. UNIPAR, Umuarama, v. 19, n. 4, p. 241-245, out./dez. 2016.

RESUMO: O arroz (Oryza sativa L.) é uma planta da família das Poaceas (gramíneas), sendo um dos cereais mais cultivados no mundo. Os fitorreguladores como auxina e giberilina podem influenciar o crescimento e desenvolvimento das plantas como o arroz. O objetivo deste estudo foi avaliar a germinação e o crescimento do arroz sob diferentes doses de fitorreguladores (auxina e giberelina). Foram conduzidos dois experimentos, o primeiro para determinar a germinação e comprimento radicular das sementes de arroz. O segundo experimento foi conduzido para determinar a altura, massa seca da parte área (MSPA) e o conteúdo nitrogênio (N) da parte aérea (NPA). Nos dois experimentos foram testadas quatro doses de auxina + giberelina: 0 (testemunha); 200; 500 e $1000 \mathrm{~mL} \mathrm{ha}^{-1}$. O delineamento experimental foi inteiramente casualizado com cinco repetições para cada tratamento nos dois experimentos. A germinação das sementes e o comprimento radicular foram aumentados com a aplicação de auxina e giberelina. A altura e o NPA foram aumentados significantemente com a aplicação de auxina e giberelina. Concluiu-se que a aplicação de auxina e giberelina na cultura do arroz aumentaram a germinação e o comprimento radicular das sementes. Além disso, aumentou a altura e o conteúdo de nitrogênio nas plantas de arroz.

PALAVRAS-CHAVES: Fitohormônios. Germinação. Poaceae.

\section{ASSESSMENT OF AUXIN AND GIBBERELLIN ON RICE GERMINATION AND GROWTH}

\begin{abstract}
Rice (Oryza sativa L.) is one of the most widely grown cereals in the world. Phytoregulators such as auxin and gibberellin can influence both growth and development of plants such as rice. The aim of this study was to assess the germination and growth of rice under different doses of phytoregulators (auxin and gibberellin). Two experiments were performed, one to determine the germination and root length of rice seeds, and the second one to evaluated height, shoot dry mass (SDM) and shoot nitrogen content (SNC). Both experiments tested four doses of auxin + gibberellin (0 (control), 200, 500 and $\left.1000 \mathrm{~mL} \mathrm{ha}^{-1}\right)$. The experimental design was completely randomized with five repetitions for both experiments. The germination and root length of rice seedlings were increased by the application of auxin and gibberellin. Rice height and SNC were significantly increased with the application of auxin and gibberellin. Thus, it can be concluded that the application of auxin and gibberellin in rice increases germination, root length, plant height and nitrogen content.
\end{abstract}

KEYWORDS: Germanation. Phytohormones. Poaceae.

\section{EVALUACIÓN DE FITORREGULADORES AUXINA Y GIBERELINA EN LA GERMINACIÓN Y CRECIMIENTO DEL ARROZ}

RESUMEN: El arroz (Oryza sativa L.) es una planta de la familia Poaceas (gramíneas), siendo uno de los cereales más cultivados en el mundo. Los fitorreguladores como auxina y giberelina pueden influir en el crecimiento y desarrollo de plantas, como el arroz. El objetivo de este estudio ha sido evaluar la germinación y el crecimiento del arroz bajo diferentes dosis de fitorreguladores (auxina y giberelina). Se realizaron dos experimentos, el primero para determinar la germinación y longitud de la raíz de las semillas de arroz. Se llevó a cabo un segundo experimento para determinar la altura, masa seca de la parte aérea (MSPA) y el contenido de nitrógeno $(\mathrm{N})$ de la parte aérea (NPA). En ambos experimentos, se ensayaron cuatro dosis de auxina + giberelina: 0 (testigo); 200; 500 y 1000 $\mathrm{mL} \mathrm{ha}^{-1}$. El diseño experimental fue completamente al azar con cinco repeticiones para cada tratamiento en ambos experimentos. La germinación de las semillas y la longitud de la raíz se incrementaron mediante la aplicación de auxina y giberelina. La altura y el NPA se incrementaron de manera significativa mediante la aplicación de auxina y giberelina. Se concluye que la aplicación de auxina y giberelina en el cultivo de arroz incrementa la germinación y longitud de la raíz de las semillas. Además, incrementó la altura de plantas de arroz con nitrógeno.

PALABRAS CLAVE: Fitohormonas. Germinación. Poaceae.

DOI: https://doi.org/10.25110/arqvet.v19i4.2016.6103

${ }^{1}$ Discentes do curso em Engenharia Agronômica - Unipar;

${ }^{2}$ Discentes do curso em Química Industrial - Unipar;

${ }^{3}$ Doutoranda do Programa de Pós-Graduação em Biotecnologia Aplicada à Agricultura da Unipar;

${ }^{4}$ Docente do Programa de Pós-Graduação em Biotecnologia Aplicada à Agricultura da Unipar. E-mail: odair@unipar.br 


\section{Introdução}

O arroz (Oryza sativa L.) é uma planta da família das Poaceas (gramíneas), sendo um dos cereais mais cultivados no mundo, com grande importância econômica (CAMPESTRINI et al., 2014; ELLI et al., 2016), sendo utilizado na alimentação de cerca de $66 \%$ da população mundial, fornecendo, aproximadamente, $20 \%$ de carboidratos e $15 \%$ da proteína per capita necessárias ao ser humano (SANTOS et al., 2006). O arroz (Oryza sativa - O. sativa) é uma importante cultura anual produzida no Brasil, representando de $15 \%$ a $20 \%$ do total de grãos colhidos no país. No Brasil, apresenta uma produção de aproximadamente 11,4 milhões de toneladas, abrangendo uma área de 2,4 milhões de hectares, sendo que o Rio Grande do Sul é o maior produtor nacional, com $69,2 \%$ do total produzido (IBGE, 2012).

Existem vários fatores que podem afetar a produção do arroz, entre estes fatores estão os reguladores vegetais, que são definidos como substâncias naturais ou sintéticas que podem ser aplicadas diretamente nas plantas para alterar seus processos vitais e estruturais para incrementar a produção e melhorar a qualidade de culturas de interesse econômico (LACA-BUENDIA, 1989). O uso de reguladores de crescimento na agricultura tem mostrado grande potencial no aumento da produtividade, embora sua utilização ainda não seja uma prática rotineira em culturas que não atingiram alto nível tecnológico (VIEIRA; CASTRO, 2001). Os fitorreguladores influenciam o crescimento e desenvolvimento das plantas, podendo promover, inibir, ou modificar os processos fisiológicos e, assim, controlar as atividades dos meristemas. Os órgãos vegetais podem ser influenciados por estas substâncias de tal maneira que a morfologia da planta é alterada (DARIO et al., 2004).

Estas substâncias sintéticas, quando aplicadas exógenamente, possuem ações similares aos grupos de reguladores vegetais conhecidos (citocininas, giberelinas, auxinas, ácido abscísico e etileno), sendo capazes de modificar processos morfológicos e fisiológicos dos vegetais (VIEIRA; CASTRO, 2001; TAIZ; ZEIGER, 2013).

As auxinas foram os primeiros hormônios vegetais descobertos, responsáveis pelo crescimento das plantas, e relacionando-se aos mecanismos de expansão celular (DARIO et al., 2004). Elas constituem a classe de hormônios vegetais mais conhecidas, sendo sintetizada a partir do aminoácido triptofano e possuindo como característica principal a capacidade de induzir o alongamento celular. $\mathrm{O}$ ácido indolbutírico (AIB) é uma auxina sintética que apresenta maior estabilidade e uma menor solubilidade que a auxina endógena, ácido indolacético (AIA), sendo considerado um dos melhores estimuladores do enraizamento (ALMEIDA et al., 2015).

As giberelinas apresentam o efeito estimulatório no processo germinativo, quando aplicadas em sementes com dormência e, também, em sementes não dormentes (ALMEIDA et al., 2015). Elas são frequentemente associadas à promoção do crescimento caulinar e a aplicação desse hormônio à plantas intactas pode induzir aumentos significativos nas suas estaturas (DARIO et al., 2004).

Assim, com a descoberta dos efeitos dos reguladores de crescimento vegetal sobre as plantas, e seu possível uso no tratamento de sementes, muitas pesquisas vêm sendo realizadas com o objetivo de melhorar quantitativa e qualita- tivamente a produtividade (CASTRO; VIEIRA, 2003; TAIZ; ZEIGER, 2013).

O objetivo do presente estudo foi avaliar a germinação e o crescimento do arroz sob doses de fitorreguladores (auxina e giberelina).

\section{Material e Métodos}

Os experimentos foram realizados no laboratório da área de Engenharia Agronômica na Universidade Paranaense - UNIPAR, Umuarama Paraná. Foram utilizadas sementes de arroz sequeiro (Oryza sativa L.) da variedade IRGA 428 CL (procedência do Instituto Rio Grandense do Arroz - IRGA), indicada para cultivo em clima seco.

Foram conduzidos dois experimentos: um para avaliar a germinação de sementes e outro para avaliar o crescimento do arroz sob diferentes doses de auxina e giberelina. Ambos experimentos tiveram o delineamento experimental inteiramente casualizado (DIC) com cinco repetições para cada tratamento.

\section{Etapa 1: Avaliação da germinação das sementes}

Foram colocadas 100 sementes de arroz em papel germitest e posteriormente essas foram umedecidas com as respectivas doses de fitohormônio, e para o tratamento testemunha foi utilizado água deionizada.

Após, cada tratamento foi acondicionado em sacos plásticos transparentes e levados em um estufa com temperatura a $30{ }^{\circ} \mathrm{C}( \pm 2)$ por até 72 horas. Foram avaliadas a percentagem de sementes germinadas e o comprimento da radícula com uma régua à 48 e 72 horas após o inicio dos tratamentos.

O experimento 1 foi montado com quatro tratamentos com cinco repetições cada, usando quatro diferentes doses do produto comercial "vital prime" a base de auxina e giberelina, conforme o fabricante - Prime Agro, Toledo, PR. As doses foram: tratamento 1 com zero $\mathrm{mL} \mathrm{ha}^{-1}$ (testemunha); Tratamento 2 com $200 \mathrm{~mL} \mathrm{ha}^{-1}$; Tratamento 3 com 500 $\mathrm{mL}$ ha $^{-1}$ e o Tratamento 4 com $1000 \mathrm{~mL} \mathrm{ha}^{-1}$.

\section{Etapa 2: crescimento do arroz sob a utilização de auxinas e giberelinas}

O experimento foi conduzido em casa de vegetação da UNIPAR, Umuarama, PR, por um período de 75 dias.

O Experimento 2 foi realizado com as mesmas doses de fitohormônio e tratamentos conforme experimento 1 . Em cada repetição por tratamento foram semeadas 10 sementes de arroz em vasos de plástico com três $\mathrm{kg}$ de substrato (areia lavada e seca + vermiculita $(1 / 1, \mathrm{v} / \mathrm{v}))$, totalizando 20 unidades experimentais. Os tratamentos foram irrigados com solução nutritiva completa conforme Hoagland e Arnon (1950) a cada dois a três dias.

Foram avaliadas a altura das plantas com uma fita métrica. A massa seca da parte aérea (MSPA) foi determinada depois de 48 h a $65^{\circ} \mathrm{C}$ em estufa com circulação de ar. Após a determinação da MSPA, esta foi moída para determinar o $\mathrm{N}$ da parte aérea (NPA) por meio da digestão sulfúrica, acompanhado da destilação pelo método de Kjeldahl conforme Silva (2009).

Os resultados foram submetidos à análise de vari- 
ância (ANOVA). As médias foram comparadas por meio do teste de Duncan $(\mathrm{p} \leq 0,05)$, utilizando o programa estatístico SPSS versão 22.0 para Windows (SPSS Inc., Chicago, IL, USA).

\section{Resultados e Discussão}

\section{Avaliação da germinação das sementes}

Observou-se efeito significativo das diferentes do- ses aplicadas de fitohormônios, na percentagem de germinação e comprimento da radícula das sementes de arroz em 48 e 72 horas após a adição de auxina e giberelina (Tabelas 1 e 2). As plantas que apresentam sistemas radiculares extensos, de elevada área superficial e comprimento, com raízes de menor diâmetro. Isso favorece uma exploração mais efetiva do solo, facilitando a adaptação em ambientes de baixa fertilidade, com restrição de água (MACHADO et al., 2004).

Tabela 1: Percentagem de germinação e comprimento da radícula (mm) das sementes de arroz 48 horas após a aplicação das diferentes doses de fitohormônios.

\begin{tabular}{ccc}
\hline Tratamento $\left(\mathbf{m L ~ h a ~}^{-\mathbf{1}}\right)$ & \% de germinação & Comp. da radícula \\
\hline 0 & $6,28 \pm 0,34 \mathrm{~b}$ & $3,00 \pm 0,32 \mathrm{c}$ \\
200 & $9,56 \pm 0,52 \mathrm{a}$ & $7,40 \pm 0,51 \mathrm{~b}$ \\
500 & $10,16 \pm 0,69 \mathrm{a}$ & $8,00 \pm 0,31 \mathrm{~b}$ \\
1000 & $10,36 \pm 0,48 \mathrm{a}$ & $12,00 \pm 0,44 \mathrm{a}$ \\
\hline Significância & $<0,001$ & $<0,001$ \\
\hline
\end{tabular}

Médias ( \pm erro padrão, $\mathrm{n}=5$ ). Médias seguidas de letras diferentes na coluna diferem estatisticamente entre si pelo teste de Duncan $(\mathrm{p} \leq$ $0,05)$.

A percentagem de germinação aumentou significativamente em todas as doses de fitohormônios testadas em relação ao controle (sem a adição de fitohormônios) (Tabelas 1 e 2). O comprimento radicular das sementes de arroz foi estimulado com a aplicação de auxina e giberelina. A dose de $1000 \mathrm{~mL} \mathrm{ha}^{-1}$ aumentou significantemente o comprimento radicular em relação às demais doses de auxina e giberelina. (Tabelas 1 e 2).

Tabela 2: Percentagem de germinação e comprimento da radícula (mm) das sementes de arroz 72 horas após a aplicação das diferentes doses de fitohormônios.

\begin{tabular}{ccc}
\hline Tratamento $\left(\mathbf{m L ~ h a ~}^{-\mathbf{1}}\right)$ & \% de germinação & Comp. da radícula \\
\hline 0 & $12,24 \pm 0,54 \mathrm{~b}$ & $12,00 \pm 0,63 \mathrm{c}$ \\
200 & $13,60 \pm 0,32 \mathrm{a}$ & $13,60 \pm 0,51 \mathrm{c}$ \\
500 & $13,76 \pm 0,53 \mathrm{a}$ & $24,80 \pm 0,86 \mathrm{~b}$ \\
1000 & $14,60 \pm 0,23 \mathrm{a}$ & $27,00 \pm 0,55 \mathrm{a}$ \\
\hline Significância & 0,011 & $<0,001$
\end{tabular}

Médias ( \pm erro padrão, $\mathrm{n}=5$ ). Médias seguidas de letras diferentes na coluna diferem estatisticamente entre si pelo teste de Duncan ( $\mathrm{p} \leq$ $0,05)$.

Dario et al. (2004), destacaram que a aplicação do fitorregulador proporcionou aumento no rendimento do arroz de até $14,37 \%$, quando comparado com o tratamento controle.

Para a cultura da soja, Leite et al. (2003), descreveram que a emergência das plantas e o comprimento das raízes foram reduzidos com o tratamento de sementes (giberelina e citocinina), porém com o decorrer do experimento a diferença no crescimento radicular desapareceu.

Rodrigues et al. (2015) avaliando a fisiologia de sementes de arroz submetidas a doses de bioestimulante, não verificaram um aumento significativo na germinação e no comprimento da radícula. Estes resultados não corroboram com os do presente estudo, porém o produto comercial usado pelos autores foi o Stimulate ${ }^{\circledR}$ que possui citocinina, giberelina e auxina, isto pode explicar a diferenças entre os resultados.

\section{Crescimento do arroz sob a utilizaçao de auxinas e gibe- relinas}

A altura do arroz aumentou significantemente com a aplicação de auxina e giberelina (Tabela 3), não tendo efeito significativo das diferentes doses de fitohormônios. No estudo de Rodrigues et al. (2015) avaliando a fisiologia de sementes de arroz submetidas a doses de bioestimulante, verificaram um aumento significativo na altura das plantas. Estes resultados corroboram com os do presente estudo, porém o produto comercial usado pelos autores foi o Stimulate ${ }^{\circledR}$ que possui citocinina, giberelina e auxina.

Santos et al. (2013), estudaram o girassol (Helianthus annuus L.) em pré-embebição de sementes por um período de $4 \mathrm{~h}$ na dose de 3,0 a 4,0 $\mathrm{mL}$ de Stimulate ${ }^{\circledR} \mathrm{L}^{-1}$ de solução, observaram que há aumento na germinação de sementes. Isso ocorre por que a giberelina estimula a síntese de enzimas que digerem as reservas armazenadas no endosperma, formando açúcares simples, aminoácidos e ácidos nucleicos, que são absorvidos e transportados para as regiões de crescimento do embrião, estimulando o alongamento celular 
e o rompimento da raiz no tegumento da semente, proporcionando maior uniformidade na germinação (STENZEL et al., 2003).

A superfície radicular é o parâmetro que melhor indica a capacidade da planta em obter água e nutrientes disponíveis ao seu desenvolvimento. Observou-se, com os resul- tados deste trabalho, que o uso de biorregulatores estimulou o maior desenvolvimento do sistema radicular das plantas de arroz, o que segundo Elli et al. (2016) possibilita melhor e maior área de exploração do solo, aspecto que influencia no maior crescimento e no desenvolvimento das plantas tratadas com os biorregulatores.

Tabela 3: Altura (cm) da planta, massa seca da parte área (MSPA - mg) e concentração de nitrogênio na parte aérea (NPA $\left.\mathrm{mg} \mathrm{g}^{-1}\right)$ do arroz sob diferentes doses de fitohormônios.

\begin{tabular}{cccc}
\hline Tratamento $\left(\mathbf{m L ~ h a ~}^{-1}\right)$ & Altura $(\mathbf{c m})$ & MSPA $(\mathbf{g})$ & NPA $\left(\mathbf{m g} \mathbf{~ g}^{-1}\right)$ \\
\hline 0 & $10,80 \pm 1,52 \mathrm{~b}$ & $0,31 \pm 0,12$ & $38,93 \pm 4,45 \mathrm{~b}$ \\
200 & $15,10 \pm 1,16 \mathrm{a}$ & $0,41 \pm 0,05$ & $46,47 \pm 5,78 \mathrm{ab}$ \\
500 & $15,68 \pm 0,70 \mathrm{a}$ & $0,42 \pm 0,06$ & $46,42 \pm 4,89 \mathrm{ab}$ \\
1000 & $14,58 \pm 0,71 \mathrm{a}$ & $0,40 \pm 0,04$ & $58,75 \pm 6,98 \mathrm{a}$ \\
\hline Significância & 0,006 & 0,668 & 0,032
\end{tabular}

Médias ( \pm erro padrão, $\mathrm{n}=5$ ). Médias seguidas de letras diferentes na coluna diferem estatisticamente entre si pelo teste de Duncan (p $\leq$ $0,05)$.

A massa seca da parte área (MSPA) de plântulas não mostrou diferença significativa entre os tratamentos, porém a adição de auxina e giberelina aumentou significantemente o nitrogênio na parte aérea (NPA), principalmente na dose de $1000 \mathrm{~mL} \mathrm{ha}^{-1}$ (Tabela 3). A concentração de hormônios existentes nas sementes, como a citocinina e giberelina, bem como o adequado equilíbrio entre eles, interferem positivamente ou não no acúmulo de massa seca de plântulas, uma vez que os bioativadores são substâncias orgânicas complexas modificadoras do crescimento, capazes de atuar na transcrição do DNA na planta, expressão gênica, proteínas da membrana, enzimas metabólicas e nutrição mineral (TAIZ; ZEIGER, 2013; ELLI et al., 2016).

$\mathrm{Na}$ cultura da soja com utilização de produto composto por reguladores vegetais de ação promotora que tem em sua constituição auxina, citocinina e giberelina, Castro e Vieira (2001) observaram resultados semelhantes, em que esses hormônios vegetais atuam como mediadores de processos fisiológicos. Os mesmos autores verificaram plantas com sistemas radiculares mais desenvolvidos, com raízes mais vigorosas e valores de massa seca, crescimento e comprimento total superiores aos encontrados nas plantas não tratadas. Esse maior desenvolvimento radicular é atribuído ao estímulo da divisão, diferenciação e alongamento celular.

Gomes et al. (2003), avaliando o efeito dos biorreguladores em variedades de feijoeiro sobre o comprimento da parte aérea e da raiz principal, concluíram que o produto apresentou efeitos positivos na variedade Valente, estimulando o crescimento da radícula, principalmente sob altas doses.

No presente trabalho, a adição de fitorreguladores aumentou a germinação, o comprimento radicular e o conteúdo de $\mathrm{N}$ na parte aérea na cultura do arroz, principalmente na dose de $1000 \mathrm{~mL} \mathrm{ha}^{-1}$, sendo esta dose portando a recomendada para estimular o crescimento desta cultura.

\section{Conclusão}

A aplicação de auxina e giberelina na cultura do arroz sequeiro (Oryza sativa L.) da variedade IRGA $428 \mathrm{CL}$ aumentaram a germinação e o comprimento radicular das sementes. Além disso, aumentou a altura e o conteúdo de nitrogênio nas plantas de arroz principalmente nas doses de
$1000 \mathrm{~mL} \mathrm{ha}^{-1}$. Com estes resultados, será necessário realizar estudos a campo para testar a possível aplicabilidade dos fitorreguradores.

\section{Agradecimentos}

Os autores agradecem à Universidade Paranaense UNIPAR pelo apoio à pesquisa.

\section{Referências}

ALMEIDA, E. M. et al. O uso de reguladores de crescimento vegetal em plantas forrageiras. Nutritime Revista Eletrônica, v. 12, n. 5, p. 4302-4308, 2015.

CAMPESTRINI, R. et al. Eficiência de genótipos de arroz no uso de nitrogênio em solos de terras altas. Pesquisa Agropecuária Pernambucana, v. 19, n. 1, p. 25-32, 2014.

\section{CASTRO, P. R. C.; VIEIRA, E. L. Aplicações de} reguladores vegetais na agricultura tropical. Guaíba: Agropecuária, 2001. 132 p.

CASTRO, P. R. C.; VIEIRA, E. L. Biorreguladores e bioestimulantes na cultura do milho. In: FANCELLI, A.L.; DOURADO NETO, D. (Eds). Milho: estratégias de manejo para alta produtividade. Piracicaba: FEALQ, 2003. p. $99-115$.

DARIO, G. J. A. et al. Influência do uso de fitorregulador no crescimento do arroz irrigado. Revista da FZVA. v. 11, n. 1, p. 86-94. 2004.

ELLI, E. F. et al. Potencial fisiológico de sementes de arroz tratadas com fitorregulador vegetal. Revista Ciência Agronômica, v. 47, n. 2, p. 366-373, 2016.

GOMES, G. F.; MARTIN-DIDONET, C. C. G.; DIDONET, A. D. Bioensaio com plântulas de feijoeiro tratadas com Stimulate ${ }^{\circledR}$ e inoculadas com Azospirillum brasilense sp. 245. Brazilian Journal of Plant Physiology, 15, Supl, p. 426, 2003. 
HOAGLAND, D. R.; ARNON, D. I. The water culture method for growing plants without soil. California Agricultural Experimental. v. 347, p. 1-32, 1950.

IBGE - INSTITUTO BRASILEIRO DE GEOGRAFIA E ESTATÍSTICA. Levantamento Sistemático da Produção Agrícola. 2012. Disponível em: $<$ http://www.ibge. gov.br/home/estatistica/ind icadores/agropecuaria/lspa/ lspa_201308_5.sht>. Acesso em: 12 set. 2016.

LACA-BUENDIA, J. P. Efeito de reguladores de crescimento no algodoeiro (Gossypium hirsutum L.).

Revista Brasileira de Fisiologia Vegetal, v. 1, n. 1, p. 109$113,1989$.

LEITE, V. M.; ROSELEM, C. A.; RODRIGUES, J. D. Gibberellin and cytokinin effects on soybean growth. Scientia Agricola, v. 60, n. 3, p. 537-541, 2003.

MACHADO, C. T. T.; MACHADO, A. T.; FURLANI, A. M. C. Variação intrapopulacional em milho para características relacionadas com a eficiência de absorção e utilização de fósforo. Revista Brasileira de Milho e Sorgo, v. 3, n. 1, p. 77-91, 2004.

RODRIGUES, L. A. et al. Avaliação fisiológica de sementes de arroz submetidas a doses de bioestimulante. Nucleus, v. 12, n. 1, p. 207-214, 2015.

SANTOS, A. B. dos. Cultivo da soca. In: SANTOS, A. B. dos; STONE, L. F.; VIEIRA, N. R. de A,. (Ed.). A cultura do arroz no Brasil. $2^{\mathrm{a}}$ ed. Santo Antônio de Goiás: Embrapa Arroz e Feijão, 2006. p. 751-794.

SANTOS, C. A. C. et al. Stimulate na germinação de sementes, emergência e vigor de plântulas de girassol. Bioscience Journal, v. 29, n. 2, p. 605-616, 2013.

SILVA, C. F. Manual de análises químicas de Solos, plantas e fertilizantes. 2 ed. Brasília, DF: Embrapa, 2009. $627 \mathrm{p}$.

STENZEL, N. M. C. et al. Superação de dormência em sementes de atemóia e fruta-do-conde. Revista Brasileira de Fruticultura, v. 25, n. 2, p. 305-308, 2003.

TAIZ, L.; ZEIGER, E. Fisiologia vegetal. 5.ed. Porto Alegre: Artmed, 2013. 918 p.

VIEIRA, E. L.; CASTRO, P. R. C. Ação de bioestimuladores na germinação de sementes, vigor das plântulas, crescimento radicular e produtividade de soja. Revista Brasileira de Sementes, v. 23, n. 2, p. 222-228, 2001 . 